\section{INFLATION TARGETING IN SRI LANKA: THE FISCAL CHALLENGE}

\author{
Kishan Abeygunawardana \\ Economist for Sri Lanka and Maldives, The World Bank
}

Sri Lanka Journal of Economic Research Volume 4 (2) June 2017 SLJER.04.02.P: pp. 93-104 Sri Lanka Forum of University Economists

\title{
BACKGROUND
}

Having recognised potential benefits, the Central Bank of Sri Lanka (CBSL) has announced that it is transitioning towards an Inflation Targeting (IT) framework. As an interim arrangement, the CBSL has adopted an enhanced monetary policy framework, which, it claims, has features of both Traditional Monetary Targeting (TMT) and Flexible Inflation Targeting (FIT) frameworks. Under this, the CBSL is said to focus on stabilising inflation in mid-single digits over the medium term, while supporting the growth objectives and flexibility in exchange rate management. Instead of reserve money, the CBSL has started using average weighted call money rate (AWCMR) as its operating target. It also claims that macro projection capacity is being strengthened at the CBSL with a view to transition towards IT.

This move has been backed by the 2016 program facilitated by the International Monetary Fund (IMF) as well. One key pillar of the Extended Fund Facility (EFF) is the transition towards IT and flexible exchange rate. The inclusion of a Monetary Policy Consultation Clause in the EFF is a clear signal of the direction. Under this Clause, if the year-on-year inflation falls outside the outer bands specified, the authorities will have to complete a consultation with the IMF which would focus on: (i) the stance of monetary policy and whether the Fund-supported program remains on track; (ii) the reasons for the deviation; and (iii) on proposed policy response. When the consultation with the IMF is triggered, access to Fund resources would be interrupted until the consultation takes place and the relevant program review is completed.

This paper explores the need to tackle fiscal dominance over monetary policy as a precondition for CBSL's implementation of IT.

\section{AN INTRODUCTION TO IT}

An IT framework is one in which a numerical inflation target is publicly announced by a monetary authority (in the present case, the CBSL), which then commits to price stability as the primary goal of monetary policy, assumes accountability for the

The views and opinions expressed in this article are those of the author and do not reflect the institution he is attached to. The author is grateful to Dr. Chandranath Amarasekara of the Central Bank of Sri Lanka for his valuable comments. Author could be contacted on kabeygunawardana@,worldbank.org. 
attainment of the inflation target, adjusts a policy instrument in a way consistent with the target, and proceeds to pursue a transparent monetary policy strategy towards these ends (Mishkin, 2004). Within such a framework, the performance of the monetary authority is itself measured against the inflation target.

Many economists attach significance to the transparency resulting from IT (Sims, 2005; Walsh, 2009). The implementation of IT also appears to have significantly reduced inflation and inflation volatility in developing countries. Even where inflation target ranges are missed, as is frequently the case in most IT countries, inflation and growth performance under IT have been found to compare favourably with the performance of countries under non-IT frameworks (Rogers, 2009).

Since its introduction in New Zealand in 1989, IT has spread among advanced, low, and lower-middle income countries, with over 35 countries having formally adopted IT as of March 2015 (IMF, 2015). The particular focus of monetary policy operations on price stability, meanwhile, is an even more widespread phenomenon: as illustrated in a survey by Laurens et al. (Central Bank Independence, Accountability, and Transparency: A Global Perspective, 2009), 95 percent of 181 countries covered had explicitly identified price stability as one of the primary objectives of their monetary policy and had prioritised price stability over other objectives of monetary policy. ${ }^{1}$

\section{IMPLEMENTING IT}

Implementation of and IT framework could be time consuming. On average, countries take 7.8 years to complete implementation of an IT framework in full (Rose, 2013). ${ }^{2}$ However, the time consumed in the process varies significantly across jurisdictions, and Laurens et al. (2015) suggest that each country should undertake implementation at a pace appropriate to its particular context.

Certain initial conditions, although they are not strict prerequisites, prove necessary in order to support the implementation of an IT framework in the short-to-medium term (Carare et al., 2002):

\footnotetext{
${ }^{1}$ Overly focusing on inflation and pursuing it as the only objective of monetary policy would inevitably lead to the neglect of other objectives (Friedman, 2004). At present, therefore, monetary authorities implementing inflation targeting typically act in a manner consistent with a concern not only for inflation, but also for real economic stability, also taking into account the potential impact of their policies on interest rate, exchange rate stability and financial system stability (Woodford, 2013; Svensson, 2009). This practice is known as 'flexible inflation targeting. This has become more prominent in the aftermath of the Global Financial Crisis.

${ }^{2}$ Computed using the dataset collected by Rose, 2003.
} 
1. A mandate to pursue an inflation objective and the accountability of the central bank in meeting this objective

(a) A central bank should have a de facto mandate to pursue the inflation target, and sufficient discretion and autonomy to set its monetary instruments accordingly.

(b) The public should be informed about the monetary policy framework and the conduct of monetary policy.

2. The need to ensure that the inflation target will not be subordinated to other objectives

(a) Monetary policy should not be dominated by fiscal priorities; the government should raise the bulk of its funding in financial markets, and government access to central bank credit should be strictly limited.

(b) The external position should be strong enough to enable monetary policy to pursue the inflation target as primary objective.

(c) At the outset of full-fledged IT, inflation should be low enough to ensure a reasonable degree of monetary control.

3. The financial system is developed and stable enough to implement the framework

(a) There should be sufficient financial stability to enable monetary policy to pursue the inflation targets and not be sidetracked by concerns about the health of the financial sector.

(b) Financial markets should be sufficiently well developed to enable monetary policy to be implemented using market based instruments and to ensure that the conduct of monetary policy is not complicated by weaknesses in financial market infrastructure.

4. The need for proper tools to implement monetary policy in support of the inflation target

(a) A central bank should be in a position to influence the inflation through its policy instruments and have a reasonable understanding of the links between the stance of policy and inflation.

(b) Exchange rate objectives must be clearly subordinated to the inflation target. Therefore the central bank should endeavour to make clear that foreign exchange market interventions and changes in the policy interest rate intended to influence the exchange rate are only aimed at smoothing the effects of temporary shocks.

(c) Fiscal policy and debt management activities should be coordinated in support of the inflation target. 
Some of the above conditions are identified as more likely than others to serve as binding constraints to the implementation of IT within the Sri Lankan monetary management framework. The present study, in its attempt to explore the feasibility of IT in a context of seemingly fiscal dominance of monetary policy in Sri Lanka, is primarily concerned with item 2(a); namely, that: 'monetary policy should not be dominated by fiscal priorities; the government should raise the bulk of its funding in financial markets, and government access to central bank credit should be strictly limited.'

\section{FISCAL CONSIDERATIONS IN IMPLEMENTING IT}

While Carare et al. (2002) do not include a strong fiscal position as an essential condition for the implementation of IT frameworks, ${ }^{3}$ they underscore the need that monetary policy is not dominated by fiscal operations. In the absence of fiscal policy backing, monetary policy proves ineffective at containing inflation (Loyo, 2000): an empirical observation supported by the fiscal theory of price level, which argues that fiscal policy influences price level and that, in order to control inflation, government finances must be sustainable (Leeper, 1991; Woodford, 1994, 1995 and 2001).

The vast majority of central banks adopting IT seem to have done so in a conducive fiscal environment; the others, at the very least, have not been experiencing fiscal stress at the point of transition. ${ }^{4}$

In contrast, Sri Lanka's fiscal landscape is characterised by high deficit ${ }^{5}$, debt, interest burden and rising contingent liabilities, as well as a high interest cost to revenue ratio which has resulted in liquidity management difficulties and a rigid fiscal budget. While a challenging fiscal landscape does not necessarily render the implementation of IT impossible, it could potentially derail the achievement of targets in the event the fiscalmonetary relationship is biased towards the former.

\footnotetext{
${ }^{3}$ In general, a country needs to strengthen its fiscal position prior to the transition to inflation targeting.

${ }^{4}$ Out of a sample of 18 IT countries, 14 had an average of below 5 percent fiscal deficits for the three years immediately prior to transition to IT while 15 countries had a public debt to GDP ratio of less than 60 percent.

${ }^{5}$ An International Monetary Fund (IMF) Extended Fund Facility extended to Sri Lanka in 2016 requires that the fiscal deficit be reduced from 7.6 percent of GDP in 2015 to 3.5 percent of GDP by 2020. Achieving this ambitious deficit target could be helpful for the CBSL to restrict year-on-year inflation within the bands specified by the IMF under the same programme.
} 


\section{FISCAL-MONETARY RELATIONSHIP: INTERNATIONAL EXPERIENCE}

Literature suggest that IT central banks typically have a high degree of instrument or operational autonomy. Rogers (2009) finds that in several emerging market economies, revisions to central bank acts have explicitly ruled out the provision of credit to the government, eliminated government vetoes over policy decisions, and strengthened measures to insulate central bank policy decision-makers from potential pressures from the government. A study of central bank financing extended to fiscal operations in 152 countries by Jácome et al. (2012) reveal the following findings. (a) in most advanced countries, central banks do not finance government expenditure; (b) in a large number of emerging and developing countries, short-term financing is allowed in order to smooth out tax revenue fluctuations; (c) in most countries, the terms and conditions of these loans are typically established by law, such that the amount is capped at a small proportion of annual government revenues, loans are priced at market interest rates, and their maturity falls within the same fiscal year; and (d) in the vast majority of countries, financing other areas of the state, such as provincial governments and public enterprises, is not allowed. It is noted that while many European countries impose strict prohibitions, Asian and African countries provide some leniency for central bank funding. Latin American countries seem to have more stringent legal restrictions, with some countries such as Brazil, Chile, Guatemala (all are IT central banks) banning central bank financing to the government at the constitutional level.

The Jácome et al. (2012) study reveals that there are clear restrictions for the amounts that could be lent to the governments. In most countries, advances and loans cannot exceed 10 percent of government revenues of the previous fiscal year or an average of the last three fiscal years. Moreover, many countries prohibit purchasing of securities by the central banks in the primary market except for the purpose of facilitating monetary policy operations.

\section{FISCAL-MONETARY RELATIONSHIP IN SRI LANKA; ARE THERE SIGNS OF FISCAL DOMINANCE?}

In Sri Lanka, the fiscal-monetary relationship is broadly defined in law. The Monetary Law Act, No. 58 of 1959 (MLA) of Sri Lanka, which established the CBSL, provides for provisional advances to be granted to the government fiscal operations. According to Section 89 of the MLA, "The Central Bank may make direct provisional advances to the Government to finance expenditures authorized to be incurred out of the Consolidated Fund... the total amount of such advances outstanding at any time shall not exceed ten per centum of the estimated revenue of the Government for the financial year in which they are made". It is noted that, by allowing the government to receive financing based on the 'estimated' revenue, the CBSL has to tolerate the burden of optimistic revenue 
estimates in the successive budgets as Sri Lanka has a history of actual revenue disappointing the budget (Exhibit 1). This setting seems contrary to the international practice that the threshold of possible monetary authority financing for a particular year is computed based on the past fiscal year revenues or average of past three years' revenues. Moreover, the MLA is silent of the determination of the interest rate at which the provisional advances are granted; as a result, the CBSL does not charge interest on provisional advances.

\section{Exhibit 1: Tax Revenue - Actual vs. Projected Revenues by Budget Year}

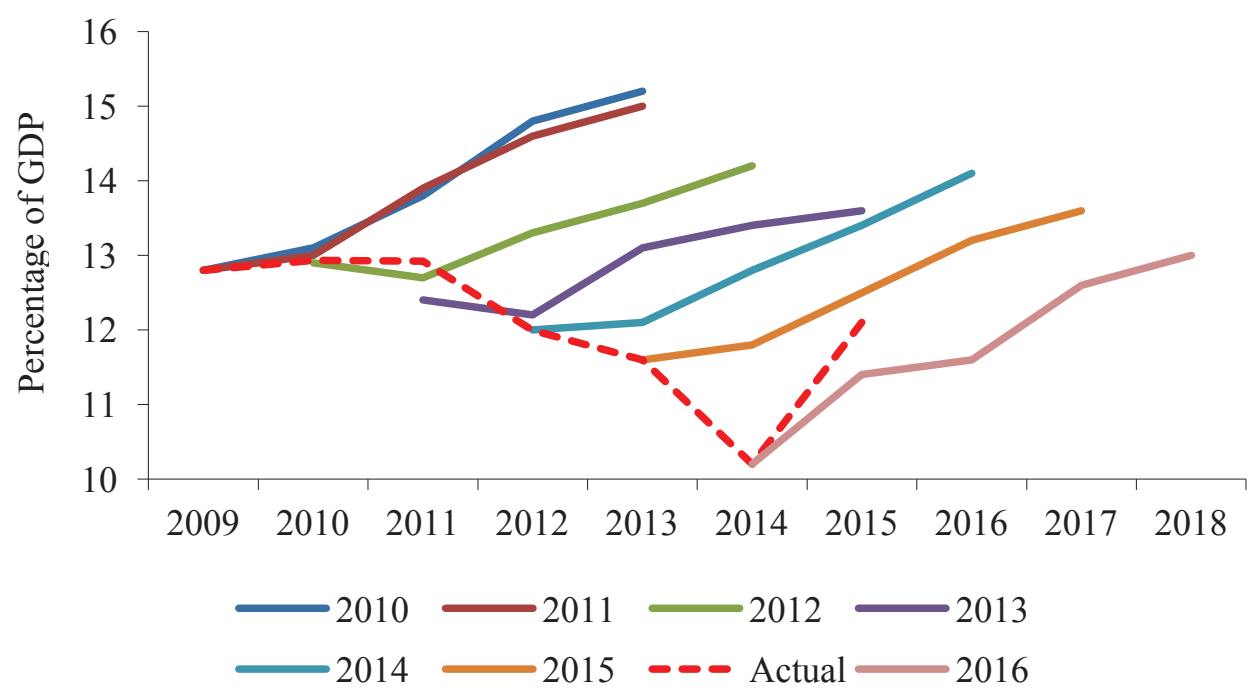

Source: Ministry of Finance and Planning.

The MLA is not specific, however, if the CBSL could finance the government through its OMOs, which are intended to be used for monetary policy purposes. The MLA allows CBSL to conduct open-market operations (a) "to increase the liquidity or stabilize the values of the securities .... in order .. to promote private investment in such securities; and to prevent or moderate sharp fluctuations in the quotations of such securities, so, however, as not to alter fundamentally movements in the market resulting from basic changes in the pattern or level of interest rates"; and (b) "to increase or decrease the supply, availability, and cost of money, in accordance with the national monetary policy as determined by the Monetary Board". Accordingly, the Section 90 (2) of the MLA permits the CBSL to hold government securities in order to conduct OMOs. 
The spirit of MLA Section 89 is to avoid excessive monetization of fiscal deficit. This position is enshrined by the Exter Report, which provides rationale for each Section of the MLA: "Many central banks and national economies have come to grief because Governments have had too easy access to central bank credit. In Ceylon it has been considered wise, at least while the Central Bank is new, to limit the direct access of the Government to Central Bank credit to its short-term, seasonal requirements for funds". Thus, one could argue that the MLA does not envisage fiscal financing through purchasing of Treasury securities in the primary market; and that the access to provisional advances is limited to short-term seasonal requirements for funds; and that the total exposure at given time to CBSL financing should not exceed 10 percent of estimated revenue of the government of the particular year. It is noted that a statutory limit of this nature is one prescription for monetary policy independence in cases where the central banks are influenced to monetize deficits.

\section{Exhibit 2: CBSL Credit to Government as a Share of Budgeted Revenue vs. Statutory Limit (including both provisional advances and bills purchased in domestic operations)}

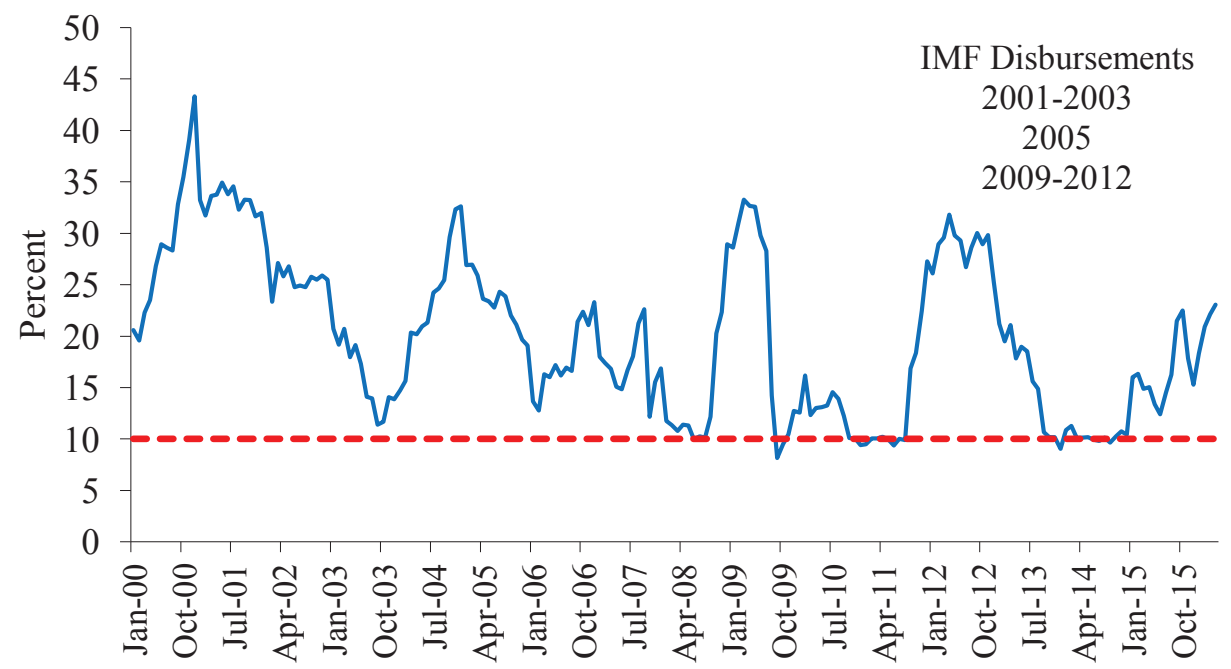

Credit to government as a share of budgeted revenue $-\infty$ Implicit statutory limit

Note: CBSL credit to government in the graph includes both provisional advances and lending through treasury bills based on the argument that MLA imposed limit on provisional advances, in spirit, is a restriction on CBSL financing of government. Lending through treasury bills was not envisaged as an instrument either by the MLA or the Exter Report.

Source: Central Bank of Sri Lanka and author's calculations. 
CBSL credit to the government seemed to have exceeded the 10 percent limit for sustained periods in the recent past (Exhibit 2). One inference coming out of this analysis is that the CBSL may have helped the government at difficult times (e.g. 2001 - peak of terrorist activity, 2008/2009 - peak of war, 2011/12 - energy subsidies, balance of payment difficulties). Interestingly, such assistance was followed by IMF programs/disbursements in response to external sector difficulties and loss of reserves created at least in part by rapid monetary expansion. Continued fiscal financing even going over the statutory limits, arguably, is an indication that the CBSL has been subject to fiscal dominance.

Assuming that the Monetary Law Act does not envisage the deficit to be monetised through Treasury securities held by the CBSL, the stock of Treasury Bills held by the CBSL could be expected to move in line with market liquidity requirements: such requirements being reflected by a strong positive correlation between the stock of Treasury Bills held by the CBSL and the net liquidity injections made by the CBSL on a daily basis. The correlation matrix in Exhibit 3 however indicates a strong positive relationship between the stock of Treasury Bills held by the CBSL and the credit extended to the government, and indicates a weak positive relationship between the former and the liquidity provided by the CBSL to the market. It may be concluded therefore that government securities held by the CBSL have been used to provide liquidity support to the government, rather than to manage liquidity in the money market.

Exhibit 3: Correlation Matrix of Selected Monetary Variables

\begin{tabular}{lccc}
\hline & $\begin{array}{c}\text { CBSL Credit to } \\
\text { Government }\end{array}$ & Net Injection & $\begin{array}{c}\text { TB Stock } \\
\text { held by the } \\
\text { CB }\end{array}$ \\
\hline CBSL Credit to Government & & $(0.04)$ & $\mathbf{0 . 8 2}$ \\
Net Injection & $(0.04)$ & & 0.21 \\
TB Stock held by the CB & $\mathbf{0 . 8 2}$ & 0.21 & \\
\hline
\end{tabular}

Source: Central Bank of Sri Lanka, author's calculations. 


\section{Exhibit 4: Market Liquidity Management and CBSL held Treasury Bill Stock}

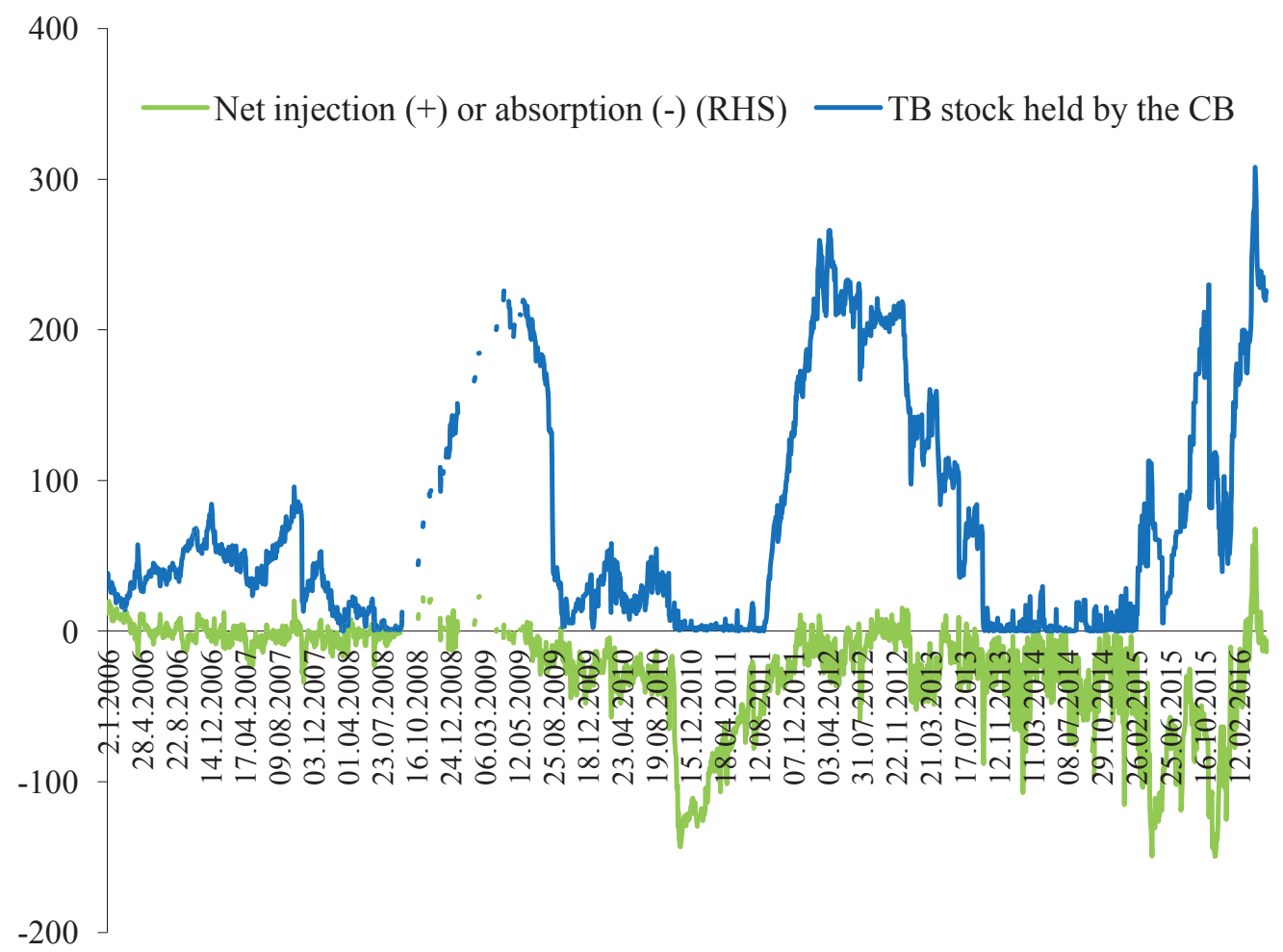

Note: $\mathrm{T}$ bill stock held by the CBSL includes gross book value of $\mathrm{T}$ bills plus total value of reverse repos and standing lending facilities minus repos with the CBSL.

Source: Central Bank of Sri Lanka.

Exhibit 4 plots the net injection (positive) or absorption (negative) against the stock of Treasury Bills held by the CBSL. During the period leading up to February $2014^{6}$, injections of liquidity by the CBSL could be expected to have been reflected in the stock of Treasury Bills, but this was not the case. Instead, the stock of Treasury Bills indicates a clear link to CBSL credit, as extended to the government (also refer Exhibit 5). Moreover, the issuance of sovereign bonds is seen to have decelerating effect on CBSL credit to government: apparently helping to manage fiscal pressures for a few months and leading to a reduction in the CBSL holding of government securities during the period.

\footnotetext{
6 The Standing Deposit Facility was uncollateralised by the CBSL in February 2014, given its implicit zero risk on local currency obligations.
} 


\section{Exhibit 5: CBSL Credit to Government and CBSL held Treasury Bill Stock}

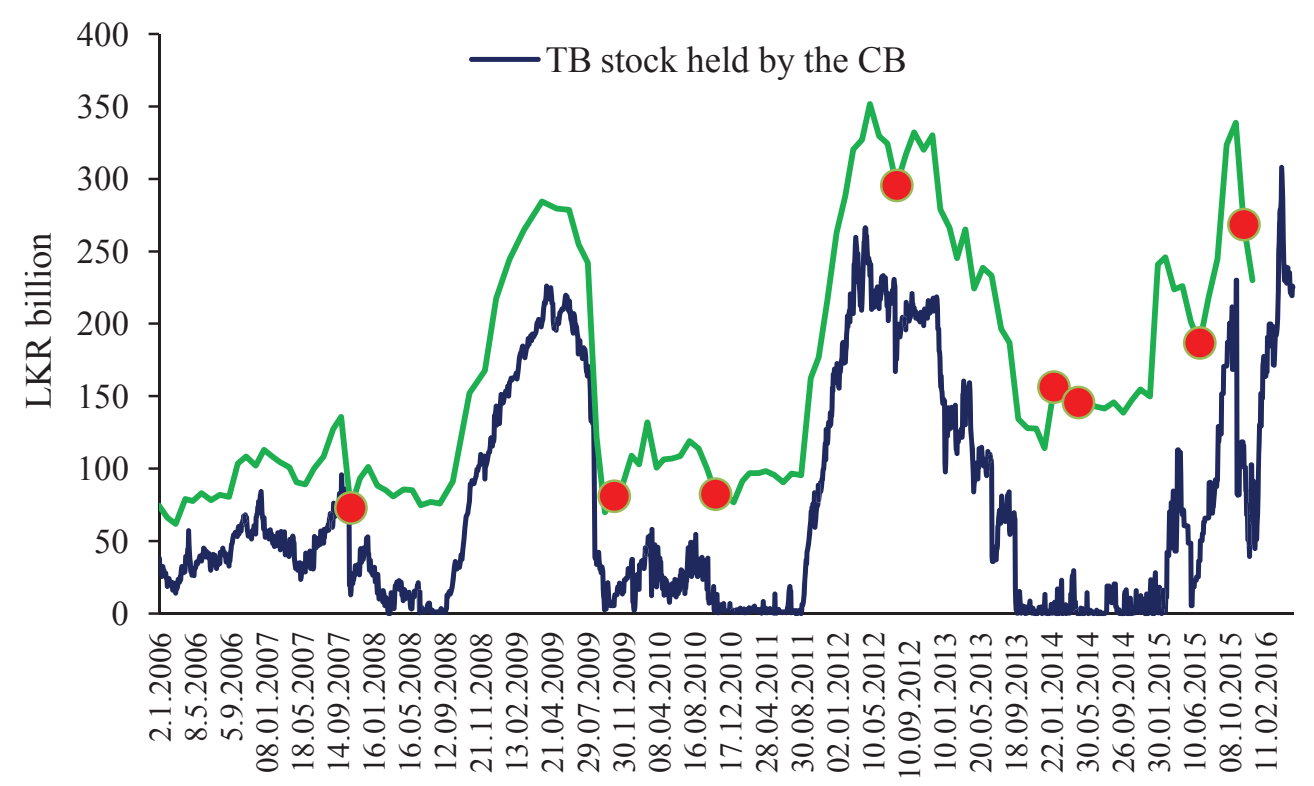

Notes: Daily data for CBSL credit to government is interpolated based on month end figures; markers in red represent months in which proceeds of sovereign bonds were received.

Source: Central Bank of Sri Lanka, author's calculations.

Therefore, it may reasonably be inferred that the stock of Treasury Bills held by the CBSL has a limited effect in facilitating market liquidity, and that it has mainly been used to provide fiscal support in a low revenue context. ${ }^{7}$

A monetary authority, even if it is an adjunct to fiscal operations, has limited space to acknowledge this fact. At the same time, a monetary authority operating within an IT framework is accountable for achieving the inflation target even where fiscal operations complicate monetary policy operations. Overcoming the fiscal dominance of monetary policy is therefore crucial to a successful transition to IT by the CBSL, and the failure to achieve the same would lead to a loss of credibility on the part of the central bank. The achievement of the ambitious deficit targets set by the IMF in working towards fiscal consolidation would be particularly decisive of the success with which IT is implemented. ${ }^{8}$ It is highly desirable, in any case, for the CBSL and the government to

\footnotetext{
${ }^{7}$ This argument is further strengthened by the fact that the CBSL did not conduct daily auctions for extended periods when the market was experiencing excess liquidity: an action which could reduce the effectiveness of monetary policy.

${ }^{8}$ It is important to note that fiscal consolidation is itself not a prerequisite for IT, but that an absence of fiscal dominance would suffice for this purpose.
} 
evaluate the relationship between fiscal and monetary policy implementation and keep monetary policy focused on stability.

\section{CONCLUSION}

The present article argues that fiscal dominance will be a key constraint to IT in a context that domestic operations of monetary policy have been an adjunct to fiscal operations in the past more than being a tool for market liquidity management. Therefore, holding the monetary authority accountable for achieving an inflation target while the fiscal operations continue to strain monetary policy operations may not bring intended outcomes and could lead to loss of credibility for the monetary authority. This situation demands reforms to the fiscal-monetary relationship if the monetary authority plans to move into an IT regime. It is commendable that the Central Bank of Sri Lanka has publicly taken on the challenge to implement an IT framework in the medium-term. However, it may now require a multi-year action plan for the transition that addresses key challenges such as a dominant fiscal policy, weak monetary transmission and demands in inflation modeling. Learning from the international experience and implementation support from relevant international agencies could be helpful for a smooth transition.

\section{REFERENCES}

Bernanke, B., Thomas, L., Frederic, M., \& Adam, P. (1999). Inflation Targeting: Lessons from the International Experience. Princeton Univeristy Press.

Carare, A., Schaechter, A., Stone, M., \& Zelmer, D. (2002). Establishing Initial Conditions in support of Inflation Targeting. Washington: International Monetary Fund.

Central Bank of Sri Lanka, various publications (Sri Lanka).

Friedman, M. (2004). Why the Federal Reserve should not Adopt Inflation Targeting. International Finance, 7(1), 129-136.

IMF. (2015). Evolving Monetary Policy Frameworks in Low-Income and other Developing Countries. Washington: International Monetary Fund.

Jácome, L., Matamoros-Indorf, M., Sharma, M., \& Townsend, S. (2012). Central Bank Credit to the Government: What Can We Learn from International Practices? Washington: International Monetary Fund. 
Laurens, B., Arnone, M., \& Segalatto, J. (2009). Central Bank Independence, Accountability, and Transparency: A Global Perspective. Washington: International Monetary Fund.

Laurens, B., Eckhold, K., King, D., Naseer, A., Maehle, N., \& Durré, A. (2015). The Journey to Inflation Targeting: Easier Said than Done. The Case for Transitional Arrangements along the Road. Washington: International Monetary Fund.

Leeper, M. (1991). Equilibria under 'Active'and 'Passive' Monetary and Fiscal Policies. Journal of Monetary Economics, 27(1), 129-147.

Loyo, E. (2000). Tight Money Paradox on the Loss: A Fiscalist Hyperinflation. Harvard University, John F. Kennedy School of Government.

Mishkin, F. (2004). Why the Federal Reserve Should Adopt Inflation Targeting. International Finance, 7(1), 117-27.

Monetary Law Act, No. 58 of 1949 (Sri Lanka).

Rogers, S. (2009). Inflation Targeting at 20: Achievements and Challenges. Washington: International Monetary Fund.

Rose, A. (2013). Surprising Similarities: Recent Monetary Regimes of Small Economies. Cambridge, Mass.: National Bureau of Economic Research.

Svensson, L. (2009). Flexible inflation Targeting - Lessons from the Financial Crisis. Amsterdam: Netherlands Bank.

Walsh, C. (2009). Inflation Targeting: What Have We Learned? International Finance, $12,195-233$.

Woodford, M. (1994). Monetary Policy and Price Level Determinancy in a Cash-inAdvance Economy. Economic Theory, 4(3), 345-380.

Woodford, M. (1995). Price Level Determinancy without Control of a Monetary Aggregate. Carnegie-Rochester Conference Series on Public Policy, 43(1), 1-46.

Woodford, M. (2001). Fiscal Requirements for Price Stability. Journal of Money, Credit and Banking, 33(3), 669-728.

Woodford, M. (2013). Inflation Targeting: Fix it, Don't Scap it. In L. Reichlin, \& R. Baldwin (Eds.), Is Inflation Targeting Dead? Central Banking after the Crisis. London: Center for Economic Policy. 